\title{
KOMPARASI MODEL E-COMMERCE UKM BANGKA BELITUNG DENGAN ANALYTICAL HIERARCHY PROCESS (AHP)
}

\author{
Hilyah Magdalena \\ Program Studi Sistem Informasi \\ STMIK Atma Luhur \\ Email: hilyahmagdalena@gmail.com
}

\begin{abstract}
ABSTRAK
Usaha Kecil dan Menengah (UKM) adalah penggerak ekonomi yang paling tahan terhadap krisis ekonomi di Indonesia. Secara nasional saat ini UKM telah mempunyai peta jalan sistem perdagangan nasional berbasis elektronik (Road Map E-Commerce) 2017 - 2019. Bagi sebagian pelaku bisnis UKM di Bangka Belitung memutuskan untuk merubah pola transaksi dari transaksi konvensional menjadi transaksi elektronik. Proses mengambil keputusan untuk merubah transaksi bisnis UKM menjadi berbasis elektronik (e-commerce) sangat dipengaruhi oleh banyak faktor. Dengan demikian proses pengambilan keputusan untuk menggunakan e-commerce bagi UKM hal menjadi pengambilan multikriteria faktor. Untuk mendukung pengambilan multikriteria faktor ini maka penelitian ini menggunakan metode Analytical Hierarchy Process (AHP). Multi kriteria faktor tersebut adalah adalah keunggulan teknologi sebesar 22,6\%, keunggulan desain web $21 \%$, keunggulan pembayaran 13,6\%, keunggulan promosi $11,7 \%$, keunggulan konsumen 10,9\%, keunggulan promosi 7,8\%, keunggulan, resiko 6,7\%, dan kelemahan $5,7 \%$. Sedangkan jenis e-commerce yang paling tinggi B2C sebesar $24,2 \%$. Hasil ini memberikan informasi untuk Dinas Perindustrian dan Perdagangan Bangka Belitung yang bekerja sama dengan Dinas Koperasi, Usaha Kecil dan Menengah Bangka Belitung untuk lebih fokus meningkatkan pelatihan dan pendampingan UKM untuk menguasai teknologi pemasaran berbasis internet.
\end{abstract}

Kata kunci: MCDM, AHP, E-Commerce, UKM.

\begin{abstract}
Small and Medium Enterprises (SMEs) are the economic drivers most resistant to the economic crisis in Indonesia. Nationally, SMEs now have a roadmap of electronic electronic commerce system (Road Map E-Commerce) from 2017 to 2019. For some SME businesses in Bangka Belitung decided to change the transaction pattern from conventional transactions to electronic transactions. The process of making the decision to change the business transactions of SMEs into electronic-based (e-commerce) is strongly influenced by many factors. Thus the decision-making process for using e-commerce for SMEs becomes multicriteria factor. To support multicriteria retrieval of this factor then this research using Analytical Hierarchy Process (AHP). Multi-factor criteria are 22.6\% technology advantage, $21 \%$ web design excellence, $13.6 \%$ payment excellence, $11.7 \%$ promotion advantage, $10.9 \%$ customer advantage, $7.8 \%$ promotion advantage, excellence, risk $6.7 \%$, and $5.7 \%$ weakness. While the type of e-commerce of the highest B2C of $24.2 \%$. These results provide information to the Department of Industry and Trade of Bangka Belitung in collaboration with the Office of Cooperatives, Small and Medium Enterprises of Bangka Belitung to further focus on improving the training and assistance of SMEs to master internetbased marketing technology
\end{abstract}

Keywords: MCDM, AHP, E-Commerce, SME.

\section{PENDAHULUAN}

Perkembangan internet saat ini mengubah cara hidup manusia modern. Hampir semua aktivitas saat ini membutuhkan dukungan internet, termasuk saat bertransaksi. Munculnya pilihan transaksi elektronik dengan berbagai platform telah memunculkan media pemasaran baru yang memberikan banyak keunggulan baru seperti akses yang cepat dan mudah serta pilihan yang beragam. Perdagangan elektronik atau e-commerce diharapkan dapat meningkatkan peluang pemasaran produk khas agar produk - produk dari UKM dapat menembus pasar Internasional. Indonesia yang mempunyai beragam produk khas yang unik yang sebagian besar dikelola oleh UKM secara konvensional harus mendorong UKM mampu memanfaatkan e-commerce secara optimal. 
Untuk mendukung partisipasi UKM dalam memanfaatkan e-commerce, ada beberapa kriteria yang penting untuk diperhatikan oleh UKM seperti beragamnya bentuk e-commerce mulai dari Business to Business (B2B), Business to Customer (B2C), Customes to Customer (C2C), Business to Administration (B2A), Customer to Administration (C2A), sampai Online to Offline (O2O). Di Indonesia sendiri saat ini klasifikasi jenis - jenis e-commerce dibagi menjadi enam menurut [1]. Selain bentuk e-commerce yang beragam, pelaku UKM sebaiknya juga memperhatikan beberapa aspek pendukung lain seperti pilihan media online dan kesiapan memanfaatkan teknologi informasi serta aspek kesadaran hukum dalam transaksi elektronik. Sebagai bentuk dukungan pemerintah pusat terhadap pertumbuhan $e$-commerce, saat ini sudah terbit peta jalan perdagangan elektronik yang tertuang dalam Peraturan Presiden Republik Indonesia No.74 Tahun 2017[2].

Di Provinsi Kepulauan Bangka Belitung, saat ini ada banyak UKM yang mulai memanfaatkan $e$ commerce. Pelaku UKM yang memanfaatkan e-commerce berasal dari beragam latar belakang industri baik itu industri rumah tangga yang memproduksi makanan khas, kain tenun cual khas Bangka, bisnis elektronik, jasa, dan lain sebagainya. Untuk wilayah Bangka Belitung berdasarkan data dari Dinas Perindustrian dan Perdagangan Bangka Belitung sampai dengan bulan Maret 2017, UKM yang telah didata sebanyak 12.843 yang terbagi menjadi usaha jenis pangan sebanyak 6807, sandang 514, kerajinan 1156, kimia dan bahan bangunan 2697, dan elektronika 1669. Dengan banyaknya jenis usaha, maka penting untuk memperhatikan faktor yang membuat konsumen percaya terhadap pelaku bisnis $e$ commerce[3].

Selain itu melihat dari kecenderungan model perdagangan elektronik yang saat ini ada di Bangka Belitung, kebanyakan pelaku bisnis UKM memilih toko online yang dalam klasifikasi e-commerce masuk dalam B2C atau C2C. Sehingga penting bagi pelaku bisnis UKM lainnya yang masih menggunakan transaksi konvensional untuk mempelajari plafform e-commerce apa yang sesuai[4]. Penelitian lain yang membahas tentang evaluasi e-commerce B2C juga dilakukan oleh[5].

Dengan mempertimbangkan berbagai aspek, baik itu beragam bentuk e-commerce dan beragam latar belakang industri, maka penelitian ini di buat dengan metode pengambilan keputusan dengan multikriteria faktor dan multi alternatif. Analytical Hierarchy Process (AHP) adalah model yang mengacu kepada metode Multiple Criteria Decision Making method (MCDM) seperti yang dilakukan oleh[6]. Dalam penelitian ini AHP akan digunakan untuk membandingkan atau komparasi antar bentuk e-commerce yang paling sesuai untuk pelaku UKM di Bangka Belitung.

\section{METODOLOGI PENELITIAN}

Penelitian ini menggunakan Metodologi Multiple Criteria Decision Making Method (MCDM) dengan model Analytical Hierarchy Process (AHP)[7]. Langkah - langkah penelitian yang dilakukan peneliti terdiri dari dua tahap utama. Tahap pertama adalah dimulai dengan melakukan studi pustaka, mempersiapkan materi kuesioner, mengumpulkan data primer maupun sekunder, dan menyusun kerangka hirarki analitik sesuai dengan konsep AHP. Hasil dari penelitian tahap pertama adalah kerangka hierarki analitik AHP. Selanjutnya adalah melengkapi kerangka hirarki analitik AHP dengan alternatif - alternatif yang akan dipilih. Proses menentukan multi alternatif dilakukan dengan mempersiapkan kuesioner tahap kedua. Hasil kuesioner tersebut disebar kepada para pakar sebagai respondennya. Hasil kuesioner tersebut kemudian dianalisis dengan skala perbandingan berpasangan Saaty. Selanjutnya skala perbandingan berpasangan tersebut dihitung bobot dan konsistensinya. Jika nilai konsistensi rasio $<=10 \%$ maka hasil pengolahan data valid, dan jika hasil lebih besar $>10 \%$ tidak valid. Hasil pengolahan data menghasilkan rangking kriteria level 1, level 2, dan level 3 sebagai alternatif. Langkah - langkah penelitian tersebut, dirangkai dalam diagram alur seperti pada gambar 1 berikut[8].

Untuk menjelaskan langkah - langkah penelitian maka gambar 1 berikut menggambarkan secara sistematis mulai dari studi kepustakaan, persiapan kuesioner, pengumpulan data, hasil pengumpulan data, kerangka hirarki analitik, persiapan kuesioner 2, analisis data, dan hasil pengolahan data yang menghasilkan rangking jenis E-Commerce yang dianggap paling sesuai dengan mayoritas pelaku bisnis UKM di Bangka Belitung. 


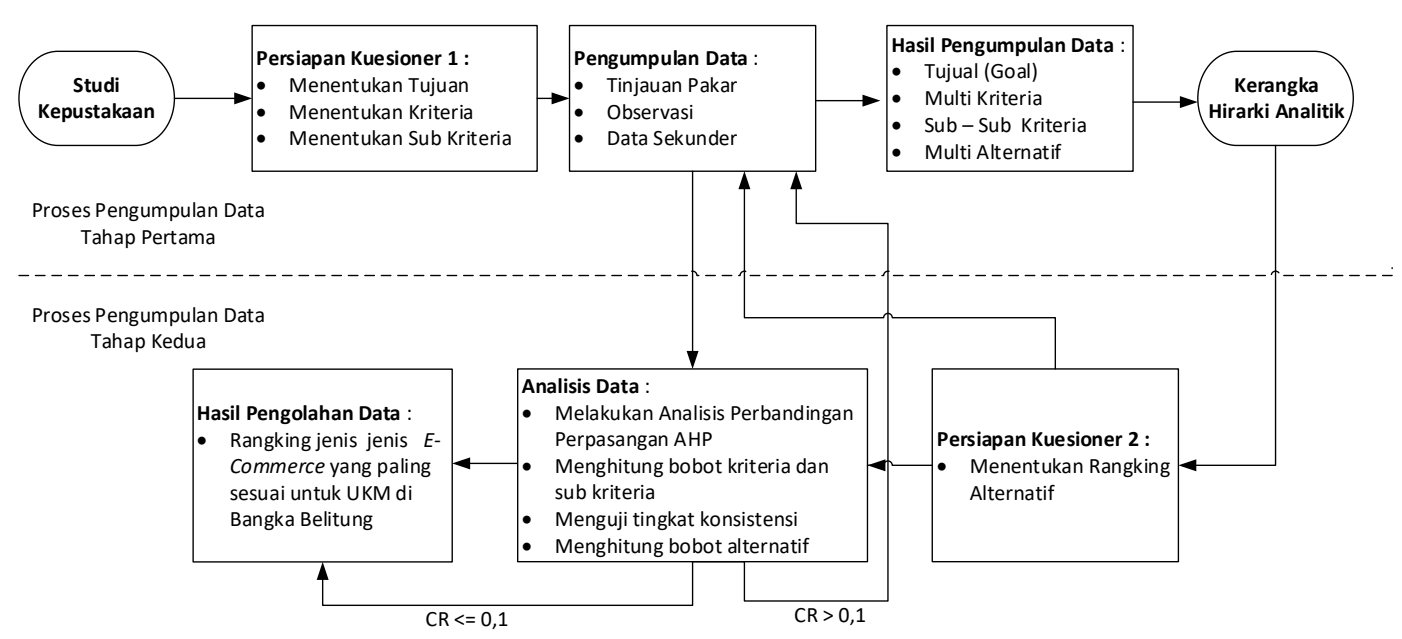

Gambar 1. Langkah - Langkah Penelitian

AHP adalah model penelitian untuk pengambilan keputusan yang mengacu pada definisi tujuan sebagai prioritas utama dari hirarki yang terbentuk dari kriteria level terendah sampai tertinggi, untuk menentukan alternatif paling penting. Kerangka hirarki analitik dengan model AHP secara umum digambarkan seperti pada Gambar 2 berikut ini,

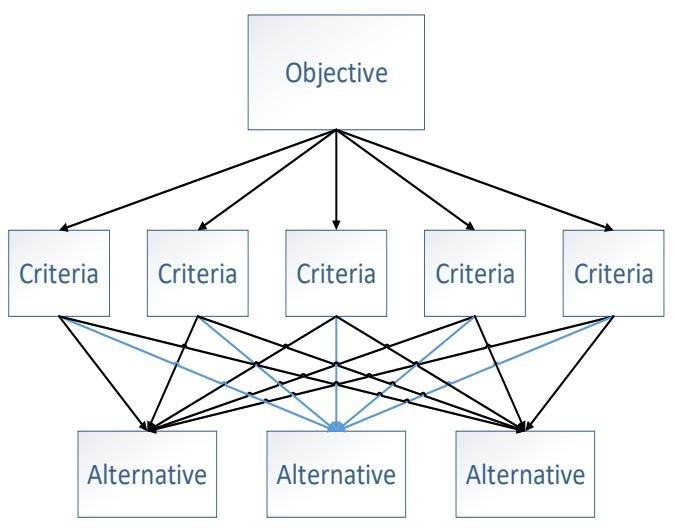

Gambar 2. Model Hirarki Analitik AHP

Setelah mendapatkan struktur hirarki, langkah selanjutnya adalah membangun matriks perbandingan berpasangan. Perhitungan matriks perbangingan berpasangan menggunakan skala fundamental bilangan mutlak Saaty, seperti yang tercantum pada tabel 1 .

Tabel 1. Skala fundamental bilangan mutlak (Saaty, 2008)

\begin{tabular}{cl}
\hline Level & \multicolumn{1}{c}{ Arti } \\
\hline 1 & $\begin{array}{l}\text { Kedua elemen sama pentingnya, kedua elemen mempunyai pengaruh yang sama } \\
\text { besar }\end{array}$ \\
3 & $\begin{array}{l}\text { Elemen yang satu sedikit lebih penting daripada elemen lainnya, pengamalan } \\
\text { dan penilaian sedikit menyokong satu elemen dibanding elemen yang lainnya. } \\
\text { Elemen yang satu lebih penting daripada yang lainnya, pengalaman dan } \\
\text { penilaian sangat kuat menyokong satu elemen dibandingkan elemen yang }\end{array}$ \\
5 & $\begin{array}{l}\text { lainnya } \\
\text { Satu elemen jelas lebih mutlak penting daripada elemen lainnya, satu elemen } \\
\text { yang kuat disokong dan dominan terlihat dalam praktek. } \\
\text { Satu elemen mutlak penting daripada elemen lainnya. Bukti yang mendukung } \\
\text { elemen yang satu terhadap elemen yang lain memiliki tingkat penegasan } \\
\text { tertinggi yang mungkin menguatkan. } \\
\text { Nilai - nilai antara dua nilai pertimbangan-pertimbangan yang berdekatan. }\end{array}$ \\
$2,3,6,8$ Nilai ini diberikan bila ada dua kompromi di antara 2 pilihan.
\end{tabular}


Dengan AHP proses pengambilan keputusan tidak lagi berdasarkan asumsi dan kata kata namun menggunakan angka yang lebih valid[9]. AHP sejatinya adalah metode matematis yang dilakukan dengan beberapa langkah yang oleh T.L.Saaty disebut dengan Seven Pillars of AHP[10].

\section{HASIL DAN PEMBAHASAN}

Hasil dari proses pengumpulan data dan membangun kerangka hirarki analitik dengan AHP untuk goal analisis komparasi jenis-jenis e-commerce untuk mendukung pengambilan keputusan perdagangan elektronik seperti pada gambar 3 berikut :

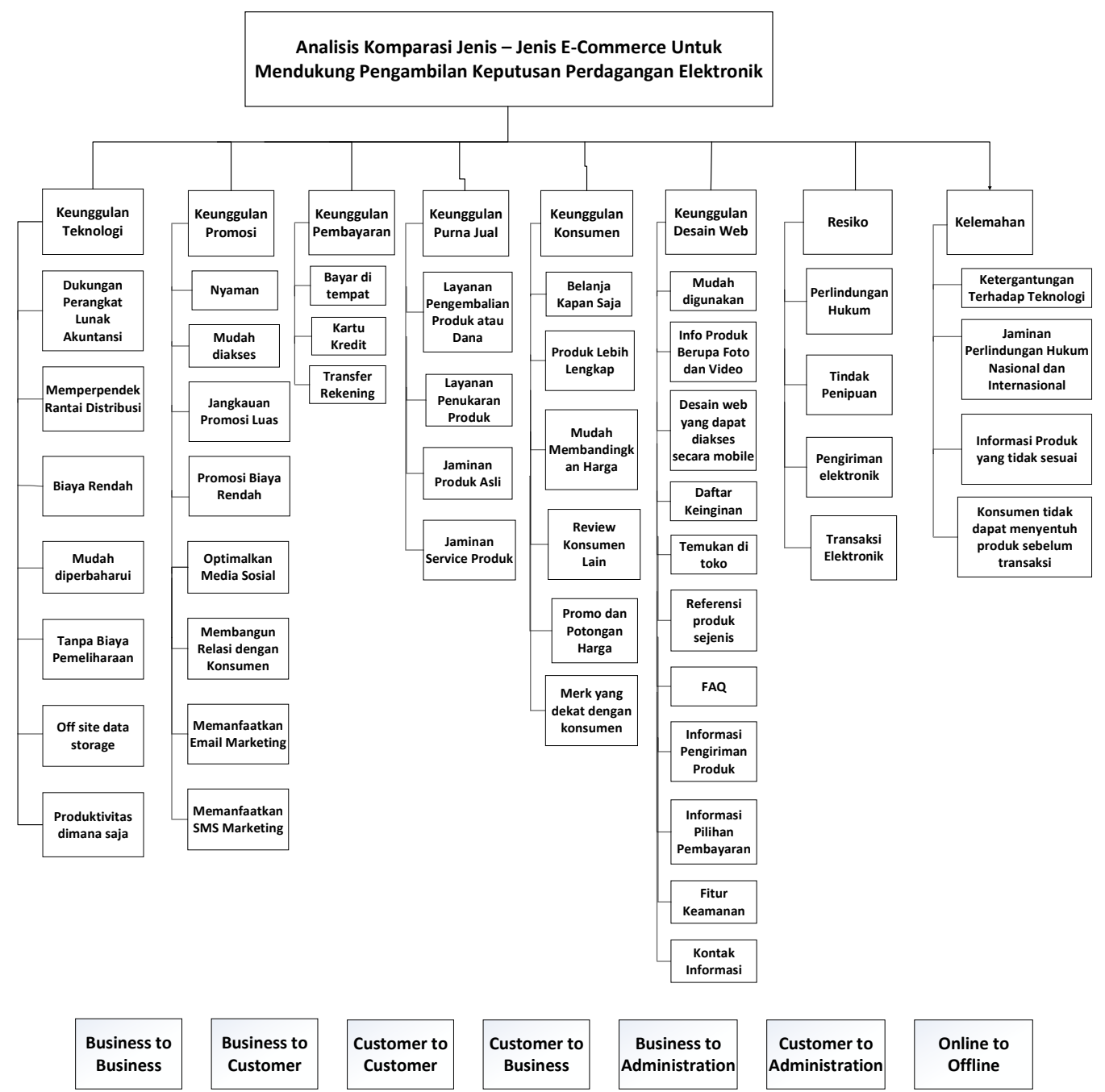

Gambar 3. Rancang Hirarki Analitik

Pada Gambar 3 terlihat kerangka hirarki analitik AHP yang terdiri dari level 0 adalah tujuan atau goal dari hirarki. Level kedua adalah kriteria level 1, kemudian sub kriteria, dan level terakhir adalah alternatif. Selanjutnya hasil pengolahan data dengan perangkat lunak Expert Choice memberikan hasil yang disajikan dalam tampilan bersisian antara kriteria level 1 dengan bobotnya serta disisi kanan adalah alternatif dengan bobotnya, seperti pada gambar 4 berikut. 


\section{Dynamic Sensitivity for nodes below: Analisis Komparasi Jenis - Jenis E-Commerce Untuk Mendukung Pengambilan Keputusan Perdagangan Elektronik}
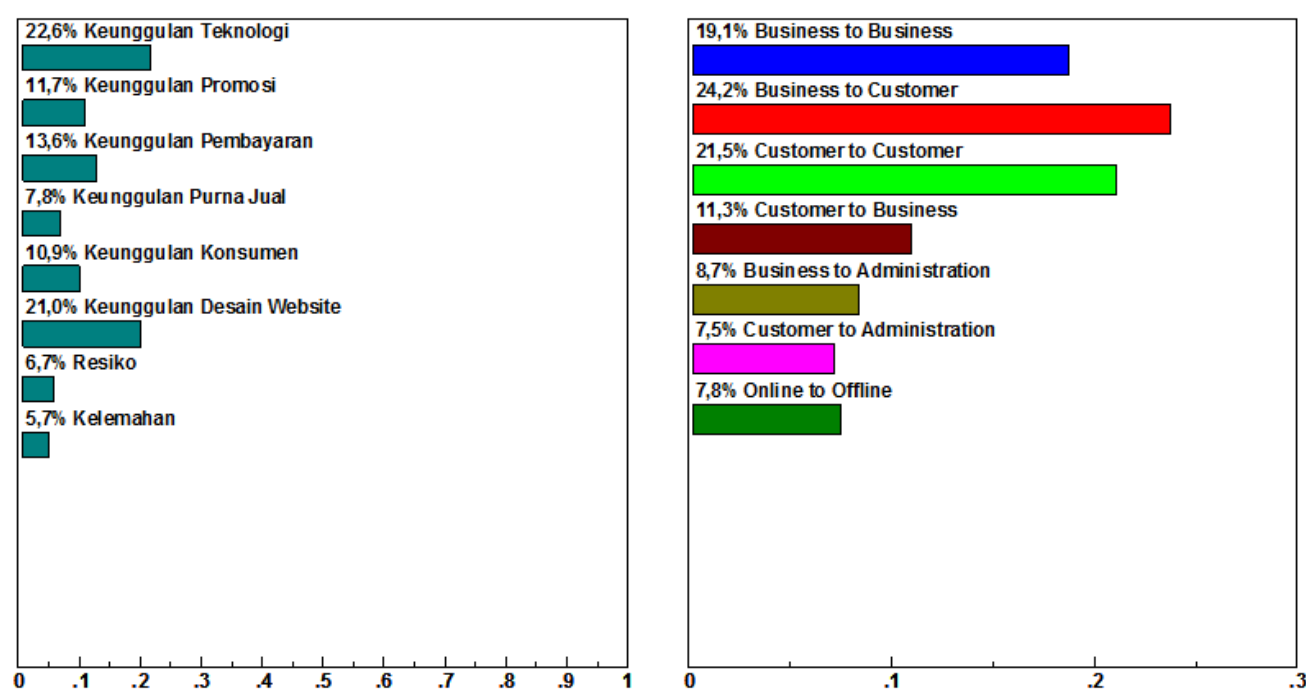

Gambar 4. Tampilan Bersisian Kriteria Level 1 Dan Alternatif

Setelah mendapat rangking kriteria dan alternatif, tahap selanjutnya adalah menguji Consistency Ratio (CR). Batas CR yang valid adalah 10\%. Berikut adalah tabel 2 yang memuat konsistensi rasio semua kriteria dari goal, kriteria level 2, kriteria level 3, telah valid.

Tabel 2. Konsistensi rasio

\begin{tabular}{|c|c|c|}
\hline No. & Matriks Perbandingan Berpasangan & $\boldsymbol{C R}$ \\
\hline 1 & $\begin{array}{l}\text { Perbandingan elemen kriteria level } 1 \text { berdasarkan sasaran Analisis Komparasi Jenis } \\
\text { - Jenis E-Commerce untuk Mendukung Pengambilan Keputusan Perdagangan } \\
\text { Elektronik }\end{array}$ & 0,02 \\
\hline 2. & Perbandingan Elemen Sub Kriteria Level II Kriteria Keunggulan Teknologi & 0,02 \\
\hline 3. & Perbandingan Elemen Sub Kriteria Level II Kriteria Keunggulan Promosi & 0,05 \\
\hline 4. & Perbandingan Elemen Sub Kriteria Level II Kriteria Keunggulan Pembayaran & 0,02 \\
\hline 5. & Perbandingan Elemen Sub Kriteria Level II Kriteria Keunggulan Purna Jual & 0,06 \\
\hline 6. & Perbandingan Elemen Sub Kriteria Level II Kriteria Keunggulan Konsumen & 0,05 \\
\hline 7. & Perbandingan Elemen Sub Kriteria Level II Kriteria Keunggulan Desain Website & 0,04 \\
\hline 8. & Perbandingan Elemen Sub Kriteria Level II Kriteria Resiko & 0,01 \\
\hline 9. & Perbandingan Elemen Sub Kriteria Level II Kriteria Kelemahan & 0,02 \\
\hline 10. & $\begin{array}{l}\text { Perbandingan Elemen Alternatif Level III Kriteria Keunggulan Teknologi Sub Kriteria } \\
\text { Dukungan Perangkat Lunak Akuntansi }\end{array}$ & 0,01 \\
\hline & $\begin{array}{l}\text { Perbandingan Elemen Alternatif Level III Kriteria Keunggulan Teknologi Sub Kriteria } \\
\text { Memperpendek Rantai Distribusi }\end{array}$ & 0,02 \\
\hline 12 & $\begin{array}{l}\text { Perbandingan Elemen Alternatif Level III Kriteria Keunggulan Teknologi Sub Kriteria } \\
\text { Biaya Rendah }\end{array}$ & 0,02 \\
\hline & $\begin{array}{l}\text { Perbandingan Elemen Alternatif Level III Kriteria Keunggulan Teknologi Sub Kriteria } \\
\text { Mudah diperbarui }\end{array}$ & 0,03 \\
\hline & $\begin{array}{l}\text { Perbandingan Elemen Alternatif Level III Kriteria Keunggulan Teknologi Sub Kriteria } \\
\text { Tanpa Biaya Perawatan IT }\end{array}$ & 0,02 \\
\hline & $\begin{array}{l}\text { Perbandingan Elemen Alternatif Level III Kriteria Keunggulan Teknologi Sub Kriteria } \\
\text { Off Site Data Storage }\end{array}$ & 0,04 \\
\hline & $\begin{array}{l}\text { Perbandingan Elemen Alternatif Level III Kriteria Keunggulan Teknologi Sub Kriteria } \\
\text { Produktivitas dimana saja }\end{array}$ & 0,01 \\
\hline 17. & $\begin{array}{l}\text { Perbandingan Elemen Alternatif Level III Kriteria Keunggulan Promosi Sub Kriteria } \\
\text { Nyaman }\end{array}$ & 0,02 \\
\hline & $\begin{array}{l}\text { Perbandingan Elemen Alternatif Level III Kriteria Keunggulan Promosi Sub Kriteria } \\
\text { Mudah diakses }\end{array}$ & 0,03 \\
\hline
\end{tabular}




\begin{tabular}{|c|c|c|}
\hline No. & Matriks Perbandingan Berpasangan & $\boldsymbol{C R}$ \\
\hline & Perbandingan Elemen Alternatif Level III Kriteria Keunggulan Promosi Sub Kriteria & \\
\hline \multirow{2}{*}{19.} & Jangkauan Promosi Luas & 0,04 \\
\hline & Perbandingan Elemen Alternatif Level III Kriteria Keunggulan Promosi Sub Kriteria & \\
\hline \multirow{2}{*}{20.} & Promosi Biaya Rendah & 0,04 \\
\hline & Perbandingan Elemen Alternatif Level III Kriteria Keunggulan Promosi Sub Kriteria & \\
\hline \multirow[t]{2}{*}{21.} & Optimalkan Media Sosial & 0,04 \\
\hline & Perbandingan Elemen Alternatif Level III Kriteria Keunggulan Promosi Sub Kriteria & \\
\hline \multirow[t]{2}{*}{22.} & Membangun Relasi dengan Konsumen & 0,03 \\
\hline & Perbandingan Elemen Alternatif Level III Kriteria Keunggulan Promosi Sub Kriteria & \\
\hline \multirow[t]{2}{*}{23.} & Memanfaatkan Email Marketing & 0,03 \\
\hline & Perbandingan Elemen Alternatif Level III Kriteria Keunggulan Promosi Sub Kriteria & \\
\hline \multirow[t]{2}{*}{24.} & Memanfaatkan SMS Marketing & 0,03 \\
\hline & Perbandingan Elemen Alternatif Level III Kriteria Keunggulan Pembayaran Sub & \\
\hline \multirow[t]{2}{*}{25.} & Kriteria Bayar di tempat & 0,02 \\
\hline & Perbandingan Elemen Alternatif Level III Kriteria Keunggulan Pembayaran Sub & \\
\hline \multirow[t]{2}{*}{26.} & Kriteria Kartu Kredit & 0,02 \\
\hline & Perbandingan Elemen Alternatif Level III Kriteria Keunggulan Pembayaran Sub & \\
\hline \multirow[t]{2}{*}{27.} & Kriteria Transfer Rekening & 0,02 \\
\hline & Perbandingan Elemen Alternatif Level III Kriteria Keunggulan Purna Jual Sub & \\
\hline \multirow[t]{2}{*}{28.} & Kriteria Layanan Pengembalian Produk dan Dana & 0,03 \\
\hline & Perbandingan Elemen Alternatif Level III Kriteria Keunggulan Purna Jual Sub & \\
\hline \multirow[t]{2}{*}{29.} & Kriteria Layanan Penukaran Prosuk & 0,04 \\
\hline & Perbandingan Elemen Alternatif Level III Kriteria Keunggulan Purna Jual Sub & \\
\hline \multirow[t]{2}{*}{30.} & Kriteria Jaminan Produk Asli & 0,02 \\
\hline & Perbandingan Elemen Alternatif Level III Kriteria Keunggulan Purna Jual Sub & \\
\hline \multirow[t]{2}{*}{31.} & Kriteria Jaminan Service Produk & 0,03 \\
\hline & Perbandingan Elemen Alternatif Level III Kriteria Keunggulan Konsumen Sub & \\
\hline \multirow[t]{2}{*}{32.} & Kriteria Belanja Kapan Saja & 0,02 \\
\hline & Perbandingan Elemen Alternatif Level III Kriteria Keunggulan Konsumen Sub & \\
\hline \multirow[t]{2}{*}{33.} & Kriteria Produk Lebih Lengkap & 0,02 \\
\hline & Perbandingan Elemen Alternatif Level III Kriteria Keunggulan Konsumen Sub & \\
\hline \multirow[t]{2}{*}{34.} & Kriteria Mudah Membandingkan Harga & 0,03 \\
\hline & Perbandingan Elemen Alternatif Level III Kriteria Keunggulan Konsumen Sub & \\
\hline \multirow[t]{2}{*}{35.} & Kriteria Review Konsumen Lain & 0,02 \\
\hline & Perbandingan Elemen Alternatif Level III Kriteria Keunggulan Konsumen Sub & \\
\hline \multirow[t]{2}{*}{36.} & Kriteria Promo dan Potongan Harga & 0,04 \\
\hline & Perbandingan Elemen Alternatif Level III Kriteria Keunggulan Konsumen Sub & \\
\hline 37. & Kriteria Merk yang dekat dengan konsumen & 0,03 \\
\hline & Perbandingan Elemen Alternatif Level III Kriteria Keunggulan Desain Web Sub & \\
\hline 38. & Kriteria Mudah digunakan & 0,02 \\
\hline & Perbandingan Elemen Alternatif Level III Kriteria Keunggulan Desain Web Sub & \\
\hline 39. & Kriteria Info Produk berupa Foto dan Video & 0,03 \\
\hline & Perbandingan Elemen Alternatif Level III Kriteria Keunggulan Desain Web Sub & \\
\hline 40. & Kriteria Desain Web yang dapat diakses kapan saja & 0,02 \\
\hline & Perbandingan Elemen Alternatif Level III Kriteria Keunggulan Desain Web Sub & \\
\hline 41. & Kriteria Daftar Keinginan & 0,01 \\
\hline & Perbandingan Elemen Alternatif Level III Kriteria Keunggulan Desain Web Sub & \\
\hline 42. & Kriteria Temukan di Toko & 0,02 \\
\hline & Perbandingan Elemen Alternatif Level III Kriteria Keunggulan Desain Web Sub & \\
\hline 43. & Kriteria Referensi Produk Sejenis & 0,03 \\
\hline & Perbandingan Elemen Alternatif Level III Kriteria Keunggulan Desain Web Sub & \\
\hline 44. & Kriteria FAQ & 0,02 \\
\hline & Perbandingan Elemen Alternatif Level III Kriteria Keunggulan Desain Web Sub & \\
\hline 45. & Kriteria Informasi Pengiriman Produk & 0,03 \\
\hline & Perbandingan Elemen Alternatif Level III Kriteria Keunggulan Desain Web Sub & \\
\hline 46. & Kriteria Informasi Pilihan Pembayaran & 0,02 \\
\hline & Perbandingan Elemen Alternatif Level III Kriteria Keunggulan Desain Web Sub & \\
\hline & Kriteria Fitur Keamanan & 0,05 \\
\hline
\end{tabular}




\begin{tabular}{|c|c|c|}
\hline No. & Matriks Perbandingan Berpasangan & $\boldsymbol{C R}$ \\
\hline & Perbandingan Elemen Alternatif Level III Kriteria Keunggulan Desain Web Sub & \\
\hline \multirow[t]{2}{*}{48.} & Kriteria Kontak Informasi & 0,03 \\
\hline & Perbandingan Elemen Alternatif Level III Kriteria Resiko Sub Kriteria Perlindungan & \\
\hline \multirow[t]{2}{*}{49.} & Hukum & 0,01 \\
\hline & Perbandingan Elemen Alternatif Level III Kriteria Resiko Sub Kriteria Tindak & \\
\hline \multirow[t]{2}{*}{50.} & Penipuan & 0,04 \\
\hline & Perbandingan Elemen Alternatif Level III Kriteria Resiko Sub Kriteria Pengiriman & \\
\hline \multirow[t]{2}{*}{51.} & Elektronik & 0,02 \\
\hline & Perbandingan Elemen Alternatif Level III Kriteria Resiko Sub Kriteria Transaksi & \\
\hline \multirow[t]{2}{*}{52.} & Elektronik & 0,03 \\
\hline & Perbandingan Elemen Alternatif Level III Kriteria Kelemahan Sub Kriteria & \\
\hline \multirow[t]{2}{*}{53.} & Ketergantungan terhadap teknologi & 0,03 \\
\hline & Perbandingan Elemen Alternatif Level III Kriteria Kelemahan Sub Kriteria Jaminan & \\
\hline 54. & Perlindungan Hukum Nasional dan Internasional & 0,03 \\
\hline & Perbandingan Elemen Alternatif Level III Kriteria Kelemahan Sub Kriteria Informasi & \\
\hline 55. & Produk yang tidak sesuai & 0,02 \\
\hline 56. & $\begin{array}{l}\text { Perbandingan Elemen Alternatif Level III Kriteria Kelemahan Sub Kriteria Konsumen } \\
\text { yang tidak dapat menyentuh produk sebelum transaksi }\end{array}$ & 0,02 \\
\hline
\end{tabular}

Tabel 2 menyajikan nilai konsistensi rasio mulai dari tujuan, kriteria level 1, kriteria level 2, sampai dengan kriteria level 3. Tabel 2 menunjukkan hasil perhitungan matriks perbandingan berpasangan mempunyai tingkat inkonsistensi kurang dari $10 \%$.

Hasil analisis komparasi beberapa jenis e-commerce yang paling sesuai dikembangkan UKM di Bangka Belitung ditampilkan pada synthesis with respect to goal seperti pada gambar 5 berikut. Synthesis with respect to goal adalah bagan batang yang memperlihatkan bobot yang diperoleh tiap alternatif. Berikut ini adalah hasil pengolahan data yang menunjukkan kesimpulan rangking alternatif terpilih dari jenis - jenis e-commerce yang paling sesuai untuk diaplikasikan para pelaku bisnis UKM di Bangka Belitung.

\section{Model Name: KEUNGGULAN E-COMMERCE}

Synthesis: Summary

\section{Synthesis with respect to:}

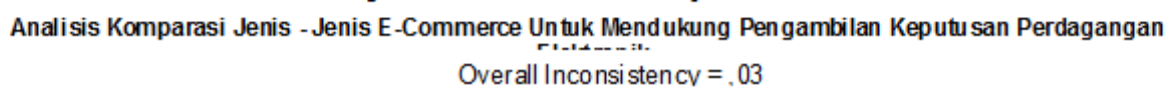

Overall Inconsistency $=.03$

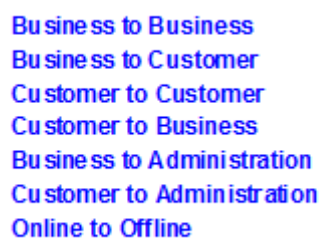

Online to Offline

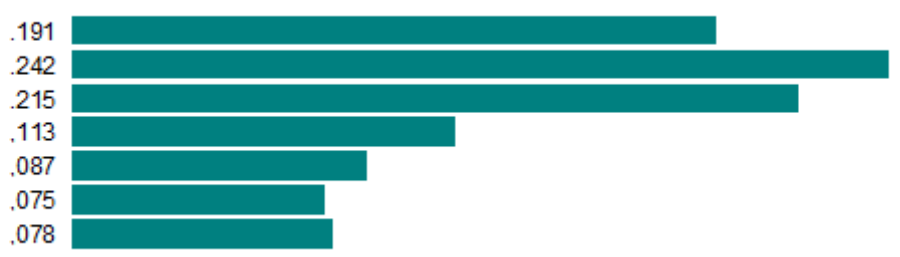

Gambar 5. Synthesis with Respect to Goal

Hasil synthesis with respect to goal memperlihatkan jenis e-commerce Business to Customer (B2C) menempati peringkat pertama dengan bobot $24,2 \%$, jenis e-commerce Customer to Customer (C2C) di peringkat kedua dengan bobot $21,5 \%$, jenis e-commerce Business to Business di peringkat ketiga dengan bobot 19,1\%. Selanjutnya ada Customer to Business (C2B) dengan bobot 11,3\%, Business to Administration (B2A) dengan bobot 8,7\%, Online to Offline $(\mathrm{O} 2 \mathrm{O})$ dengan bobot 7,8\%, dan terakhir Customer to Administration (C2A) dengan bobot 7,5\%.

Setelah para pemangku kepentingan terkait mendapatkan informasi pendukung keputusan terkait jenis - jenis e-commerce apa yang paling sesuai untuk dikembangkan pelaku bisnis UKM di Bangka Belitung, untuk mempelajari detil informasi yang terkandung dalam diagram batang pada synthesis with respect to goal, maka pada tabel 3 berikut ini disajikan secara detil berapa prioritas untuk setiap alternatif mulai dari tujuan, kriteria level 1, 2, dan 3. 
Tabel 3. Peringkat Komposit

\begin{tabular}{|c|c|c|c|c|}
\hline Goal & Level 1 & Level 2 & Alternatives & Priority \\
\hline & $\begin{array}{l}\text { Keunggulan } \\
\text { Teknologi }\end{array}$ & & Business to Business & 0,005 \\
\hline & $(L: 0,226)$ & & Business to Customer & 0,002 \\
\hline & & Dukungan Perangkat & Customer to Customer & 0,002 \\
\hline & & $\begin{array}{l}\text { Lunak Akuntansi (L: } \\
\text { O }\end{array}$ & Customer to Business & 0,002 \\
\hline & & & Business to Administration & 0,004 \\
\hline & & & Customer to Administration & 0,002 \\
\hline & & & Online to Offline & 0,001 \\
\hline & & & Business to Business & 0,01 \\
\hline & & & Business to Customer & 0,012 \\
\hline & & Memperpendek & Customer to Customer & 0,008 \\
\hline & & Rantai Distribusi (L: & Customer to Business & 0,005 \\
\hline & & & Business to Administration & 0,004 \\
\hline & & & Customer to Administration & 0,003 \\
\hline & & & Online to Offline & 0,004 \\
\hline & & & Business to Business & 0,006 \\
\hline $\begin{array}{c}\text { Komparasi } \\
\quad \text { Model }\end{array}$ & & & Business to Customer & 0,013 \\
\hline \multirow[t]{18}{*}{$\begin{array}{c}\text { E- } \\
\text { Commerce } \\
\text { untuk } \\
\text { UKM di } \\
\text { Bangka } \\
\text { Belitung }\end{array}$} & & $\begin{array}{l}\text { Biaya Rendah ( } L \text { : } \\
0,215 \text { ) }\end{array}$ & Customer to Customer & 0,014 \\
\hline & & & Customer to Business & 0,007 \\
\hline & & & Business to Administration & 0,005 \\
\hline & & & Customer to Administration & 0,004 \\
\hline & & & Online to Offline & 0,004 \\
\hline & & & Business to Business & 0,006 \\
\hline & & & Business to Customer & 0,008 \\
\hline & & & Customer to Customer & 0,007 \\
\hline & & Mudah diperbarui ( $L$ : & Customer to Business & 0,004 \\
\hline & & & Business to Administration & 0,003 \\
\hline & & & Customer to Administration & 0,003 \\
\hline & & & Online to Offline & 0,003 \\
\hline & & $\begin{array}{l}\text { Tanpa biaya } \\
\text { perawatan IT }\end{array}$ & Business to Business & 0,004 \\
\hline & & $(L: 0,206)$ & Business to Customer & 0,011 \\
\hline & & & Customer to Customer & 0,013 \\
\hline & & & Customer to Business & 0,006 \\
\hline & & & Business to Administration & 0,004 \\
\hline & & & Customer to Administration & 0,005 \\
\hline
\end{tabular}




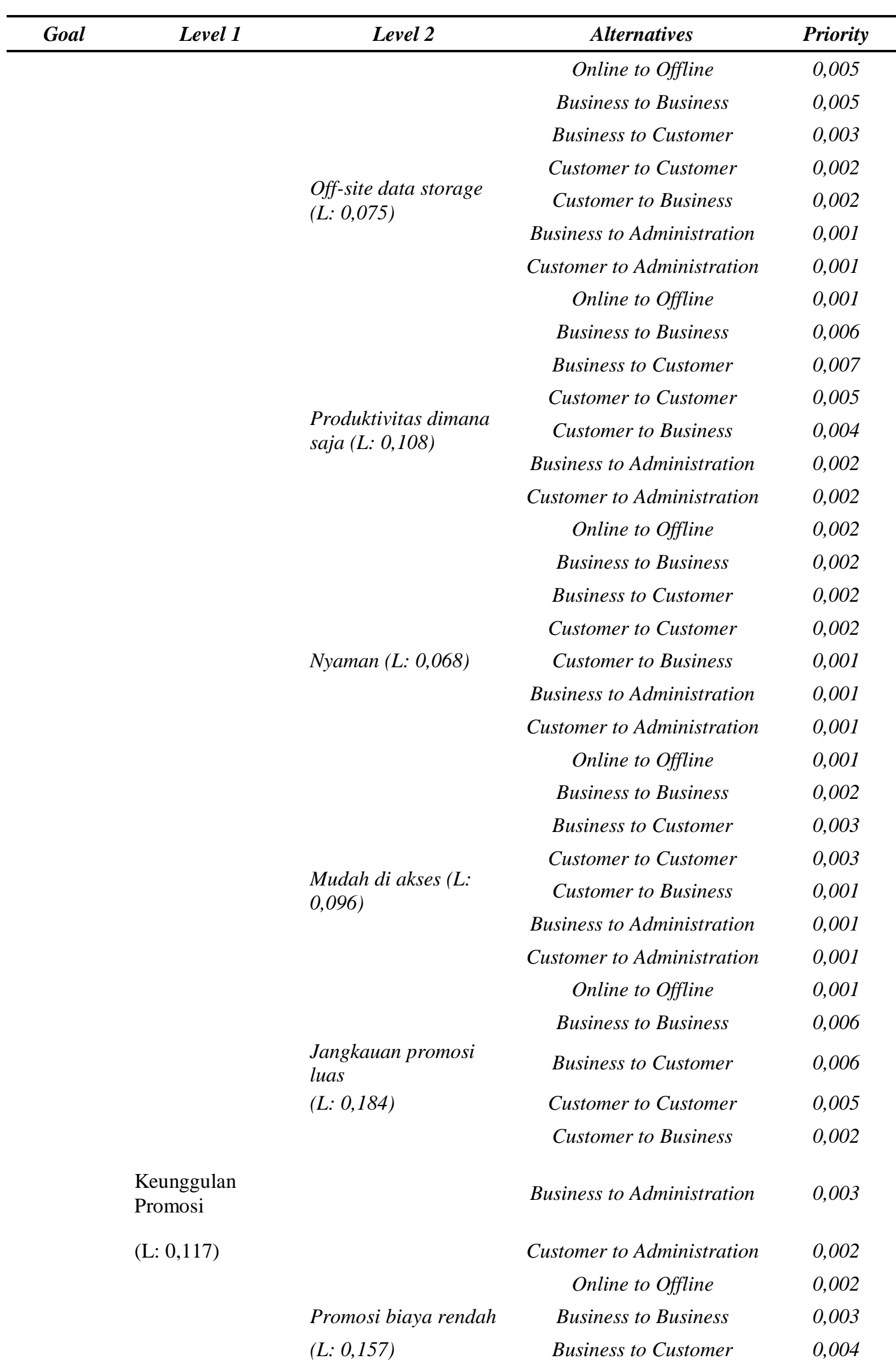




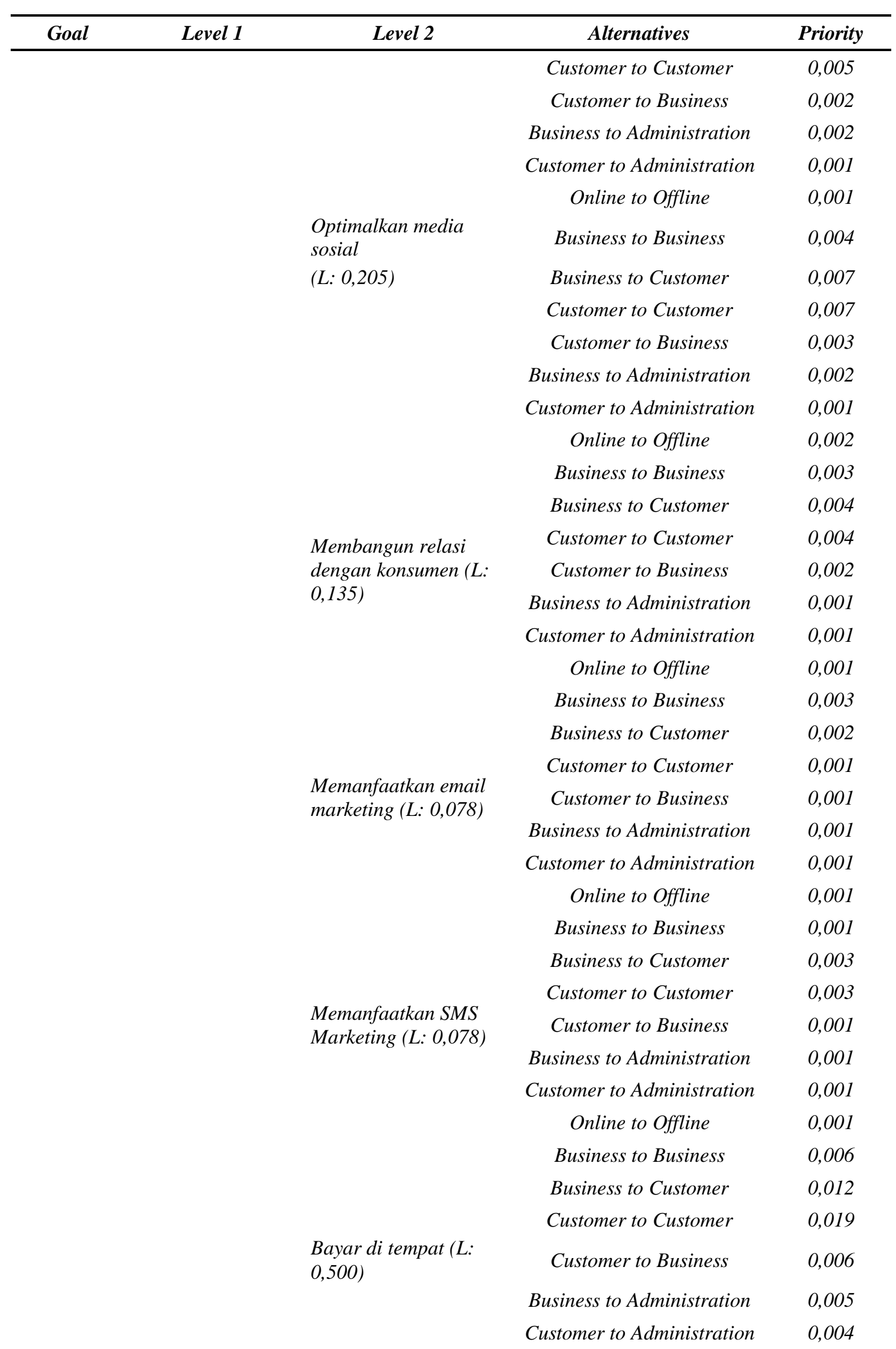




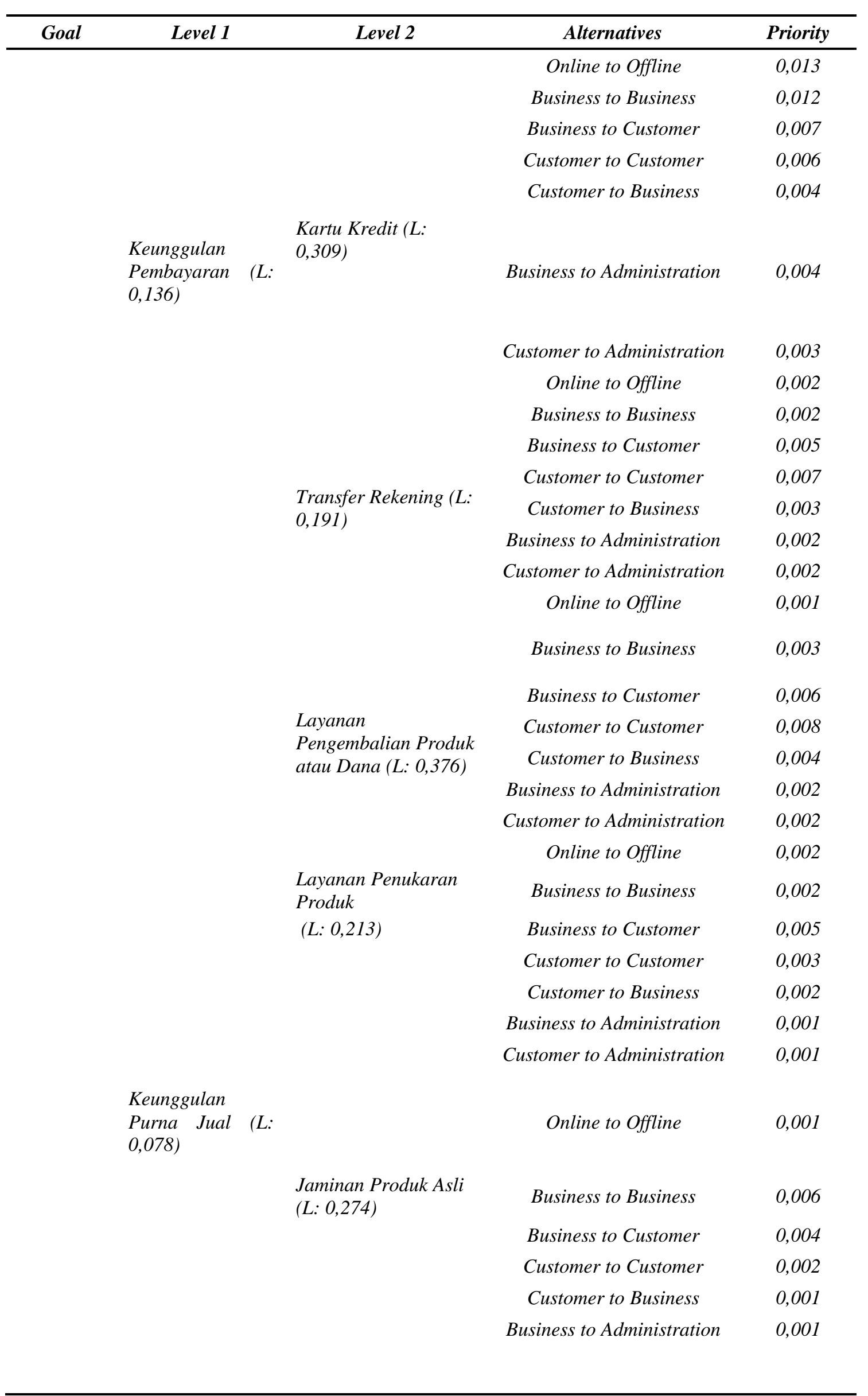




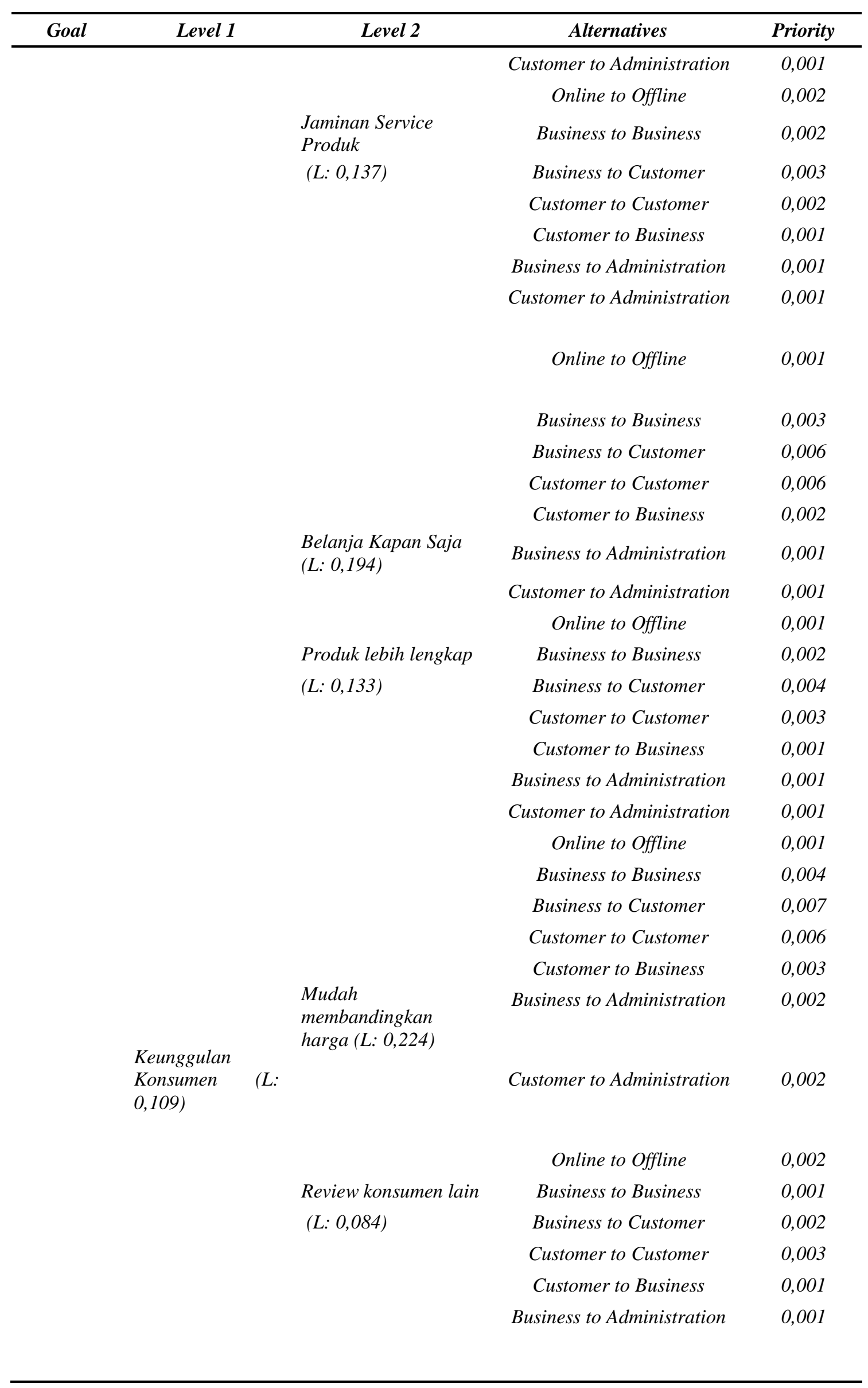




\begin{tabular}{|c|c|c|c|c|}
\hline Goal & Level 1 & Level 2 & Alternatives & Priority \\
\hline & & \multirow{11}{*}{$\begin{array}{l}\text { Promo dan Potongan } \\
\text { Harga }(\text { L: } 0,291)\end{array}$} & Customer to Administration & 0,001 \\
\hline & & & Online to Offline & 0 \\
\hline & & & Business to Business & 0,006 \\
\hline & & & Business to Customer & 0,009 \\
\hline & & & Customer to Customer & 0,007 \\
\hline & & & Customer to Business & 0,004 \\
\hline & & & Business to Administration & 0,003 \\
\hline & & & Customer to Administration & 0,002 \\
\hline & & & Online to Offline & 0,002 \\
\hline & & & Business to Business & 0,001 \\
\hline & & & Business to Customer & 0,002 \\
\hline & & \multirow{7}{*}{$\begin{array}{l}\text { Merk yang dekat } \\
\text { dengan konsumen (L: } \\
0,073)\end{array}$} & Customer to Customer & 0,002 \\
\hline & & & Customer to Business & 0,001 \\
\hline & & & Business to Administration & 0,001 \\
\hline & & & Customer to Administration & 0,001 \\
\hline & & & Online to Offline & 0,001 \\
\hline & & & Business to Business & 0,005 \\
\hline & & & Business to Customer & 0,007 \\
\hline & & \multirow{7}{*}{$\begin{array}{l}\text { Mudah digunakan (L: } \\
0,110)\end{array}$} & Customer to Customer & 0,004 \\
\hline & & & Customer to Business & 0,003 \\
\hline & & & Business to Administration & 0,002 \\
\hline & & & Customer to Administration & 0,002 \\
\hline & & & Online to Offline & 0,001 \\
\hline & & & Business to Business & 0,004 \\
\hline & & & Business to Customer & 0,007 \\
\hline & & \multirow{7}{*}{$\begin{array}{l}\text { Info Produk berupa } \\
\text { Foto dan Video (L: } \\
0,124)\end{array}$} & Customer to Customer & 0,005 \\
\hline & & & Customer to Business & 0,002 \\
\hline & & & Business to Administration & 0,002 \\
\hline & & & Customer to Administration & 0,001 \\
\hline & & & Online to Offline & 0,001 \\
\hline & & & Business to Business & 0,011 \\
\hline & & & Business to Customer & 0,011 \\
\hline & & \multirow{5}{*}{$\begin{array}{l}\text { Desain web yang } \\
\text { dapat diakses secara } \\
\text { mobile }(\text { L: } 0,189)\end{array}$} & Customer to Customer & 0,006 \\
\hline & & & Customer to Business & 0,004 \\
\hline & & & Business to Administration & 0,004 \\
\hline & & & Customer to Administration & 0,003 \\
\hline & & & Online to Offline & 0,002 \\
\hline & & \multirow[t]{3}{*}{$\begin{array}{l}\text { Daftar Keinginan }(L: \\
0,045)\end{array}$} & Business to Business & 0,001 \\
\hline & & & Business to Customer & 0,002 \\
\hline & & & Customer to Customer & 0,003 \\
\hline
\end{tabular}


Temukan di Toko (L: 0,035)

Referensi Produk Sejenis (L: 0,074)

FAQ (L: 0,056)

Informasi Pengiriman Produk (L: 0,085)

Informasi Pilihan Pembayaran (L: 0,118)
Alternatives

Priority

Customer to Business

0,001

Business to Administration

0,001

Customer to Administration

0,001

Online to Offline

0,001

Business to Business

0,002

Business to Customer

0,002

Customer to Customer

0,001

Customer to Business

0,001

Business to Administration

0

Customer to Administration

0,001

Online to Offline

0,001

Business to Business

0,004

Business to Customer

0,004

Customer to Customer

0,003

Customer to Business

0,002

Business to Administration

0,001

Customer to Administration

0,001

Online to Offline

0,002

Business to Business

0,003

Business to Customer

0,002

Customer to Customer

0,001

Customer to Business

0,001

Business to Administration

0,001

Customer to Administration

0,001

Online to Offline

0,001

Business to Business

0,004

Business to Customer

0,005

Customer to Customer

0,003

Customer to Business

0,002

Business to Administration

0,001

Customer to Administration

0,001

Online to Offline

0,001

Business to Business

0,006

Business to Customer

0,007

Customer to Customer

0,004

Customer to Business

0,003

Business to Administration

0,003

Customer to Administration

0,002

Online to Offline 
Keunggulan Desain Website (L: 0,210)

Resiko

(L: 0,067)

\section{Level 1}

Fitur Keamanan (L: 0,106)

\section{Level 2}

Kontak informasi (L: 0,057)

Perlindungan Hukum (L: 0,305)

Tindak Penipuan (L: 0,305)

\section{Pengiriman}

Elektronik

(L: 0,113)

Transaksi Elektronik (L: 0,277)
Priority

0,006

Business to Business

0,005

Business to Customer

0,003

Customer to Customer

0,002

Customer to Business

0,002

Business to Administration

0,001

Customer to Administration

0,001

Online to Offline

0,003

Business to Business

0,002

Business to Customer

0,002

Customer to Business

0,001

Business to Administration

0,001

Customer to Administration

0,001

Online to Offline

0

Business to Business

0,005

Business to Customer

0,006

Customer to Customer

0,004

Customer to Business

0,002

Business to Administration

0,003

Customer to Administration

0,002

Online to Offline

0,001

Business to Business

0,002

Business to Customer

0,003

Customer to Customer

0,006

Customer to Business

0,002

Business to Administration

0,002

Customer to Administration

0,001

Online to Offline

0,001

Business to Business

0,001

Business to Customer

0,002

Customer to Customer

0,002

Customer to Business

0,001

Business to Administration

0,001

Customer to Administration

0,001

Online to Offline

0

Business to Business

0,003

Business to Customer

0,005

Customer to Customer

0,003

Customer to Business

0,002 


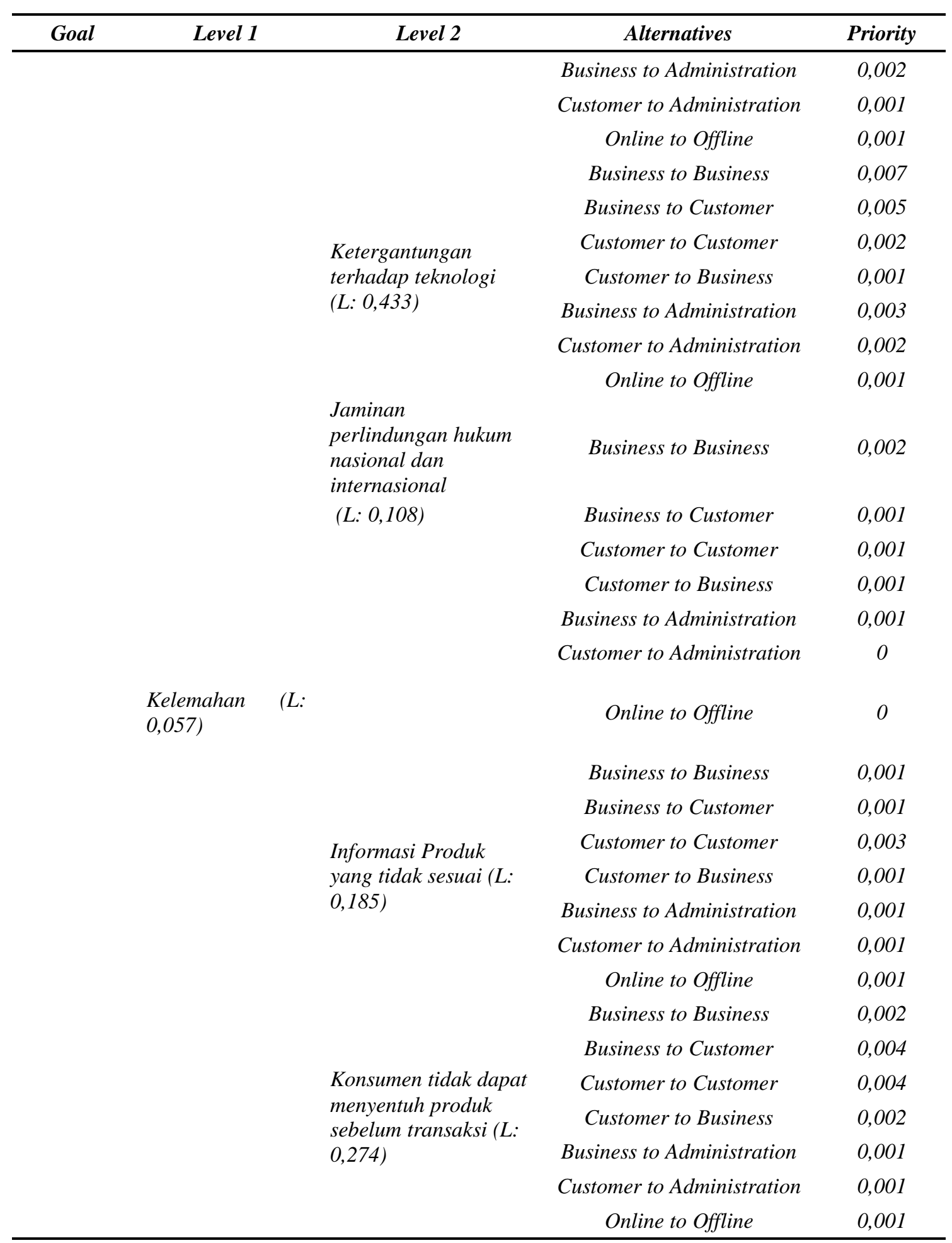




\section{KESIMPULAN}

Mengingat besarnya potensi perdagangan elektronik, maka pelaku bisnis UKM khususnya yang berada di Bangka Belitung harus mampu memanfaatkan potensi tersebut secara optimal. Perdagangan elektronik atau e-commerce mempunyai beberapa jenis dan keunggulan. Penelitian ini menyusun semua kriteria yang menjadi keunggulan e-commerce dan jenis - jenis e-commerce sebagai alternatif dalam sebuah hirarki analitik AHP. Berdasarkan hasil analisa hirarki analitik AHP dan pengolahan data dengan perangkat lunak Expert Choice menunjukkan bahwa jenis e-commerce yang paling banyak dipilih oleh pelaku bisnis UKM di Bangka Belitung adalah Business to Customer (B2C) dengan bobot mencapai $24,2 \%$. Sedangkan kriteria yang paling penting bagi pelaku bisnis UKM di Bangka Belitung dalam memanfaatkan e-commerce adalah keunggulan teknologi dengan bobot mencapai $22,6 \%$. B2C menjadi model perdagangan elektronik yang paling sesuai karena sebagian besar pelaku bisnis di Bangka Belitung berkecimpung dalam usaha produksi makanan khas dan kemudian menjualnya secara konvensioanl. Masalah pemasaran dan promosi inilah yang mendapat keuntungan paling besar dengan adanya perdagangan elektronik. Maka hasil penelitian ini menunjukkan bahwa jenis B2C adalah model perdagangan elektronik yang paling sesuai dikembangkan UKM Bangka Belitung, dan untuk memaksimalkan manfaat B2C bagi UKM maka perlu peningkatan pengetahuan teknologi informasi khususnya yang terkait dengan pemasaran berbasis online.

\section{DAFTAR PUSTAKA}

[1] M. Pradana, "Klasifikasi Jenis-Jenis Bisnis E-Commerce di Indonesia”, Jurnal Neo-bis Volume 9, No. 2, Des 2015, pp. 32-40.

[2] Peraturan Presiden Republik Indonesia No.74 Tahun 2017 Tentang Peta Jalan Sistem Perdagangan Nasional Berbasis Elektronik (Road Map E-Commerce) tahun 2017 - 2019.

[3] B. Kaur, S. Madan, "Identifying Customers' Preference of Trust Factors in Adoption of B2C ECommerce in India", International Journal of Computer Science And Technology IJCST Vol. 4, Issue 2, April - June 2013, pp. 736-739.

[4] Z. Qi, S. Dong, Q. Li, M. Ren, J. Wang, "Research on evaluating B2C shopping platform", Journal of Chemical and Pharmaceutical Research, 2014, 6(4):474-480

[5] K. Taş, Y. A. Nanehkaran, "Evaluation of E-Commerce Service Quality Using the Analytic Hierarchy Process", International Journal of Scientific \& Engineering Research, Volume 4, Issue 8, August-2013, pp. 2147-2153

[6] S. Aydin, C. Kahraman, "A Modified Fuzzy Analytic Hierarchy Process Based Multicriteria Decision making Methodology for Assessing E-commerce Website Quality:A Case Study in Turkey", Proceedings of the World Congress on Engineering 2011 Vol II WCE 2011, July 6 - 8, 2011, London, U.K.

[7] N. F. Aziz, S. Sorooshian, F. Mahmud, "MCDM-AHP Method In Decision Makings", Asian Research Publishing Network (ARPN) Journal of Engineering and Applied Sciences VOL. 11, NO. 11, JUNE 2016. pp. $7212-7220$.

[8] T. Bo, W. Jia, Y. Lei, "Recommended Trust Evaluation in B2C E-Commerce Based on Fuzzy Analytic Hierarchy Process", National Natural Science Fund61005015/F030403, Natural Science Fund(12ZR1409900)

[9] T. L. Saaty, M. P. Niemira, "A Framework for Making a Better Decision", RESEARCH REVIEW, V. 13, No. 1, 2006, pp. $1-4$ 
[10] T. L. Saaty and L. G. Vargas, "Models, Methods, Concepts \& Applications of the Analytic Hierarchy Process", International Series in Operations Research \& Management Science 175, DOI: 10.1007/978-1-4614-3597-6_2, Springer Science+Business Media New York 2012 